\title{
Formy realizacji aktu mowy ODMAWIANIE $w$ języku niemieckim na przykładzie listów odmownych na podania o pracę
}

Forms of the Implementation of the Speech Act REFUSAL in German: An Analysis of Rejection Letters for Job Applications

\begin{abstract}
A REFUSAL is an act of speech that belongs to the so-called critical speech acts. Its implementation poses a threat to the interaction balance between the sender and the recipient. For this reason, language uses resort to a variety of verbal and non-verbal strategies related to REFUSAL. A special case of the implementation of this speech act are letters of rejection for job applications, in which the refusal should - directly or indirectly - be expressed. Senders of this genre of tents formulate the refusal in different ways. This article examines the forms in which the speech act REFUSAL is implemented in German, drawing from the aforementioned genre. The aim is to identify strategies used in the realization of this speech act and to create a typology of forms used in the linguistic uses of REFUSAL.
\end{abstract}

Key words: rejection letters for job applications, refusal, REFUSAL, forms of refusal, refusal strategies

Abstract: Odmowa to akt mowy, należący do tzw. krytycznych aktów mowy. Jego realizacja powoduje zagrożenie dla równowagi interakcyjnej między nadawcą i odbiorcą. $Z$ tego też powodu użytkownicy języka stosują różne werbalne i niewerbalne strategie związane z realizacją ODMAWIANIA. Szczególnym przypadkiem realizacji tego aktu mowy są listy odmowne na podania o pracę, w których powinna pośrednio lub bezpośrednio - zostać wyrażona odmowa. Nadawcy wskazanego gatunku tekstu formułują ją $w$ różny sposób. Przedmiotem artykułu są formy realizacji aktu mowy ODMAWIANIE $w$ języku niemieckim na podstawie wskazanego gatunku tekstu. Celem jest skierowanie uwagi na strategie stosowane $w$ realizacji tego aktu mowy oraz próba stworzenia typologii form używanych $w$ językowej realizacji ODMAWIANIA.

Słowa kluczowe: listy odmowne na podania o pracę, odmowa, ODMAWIANIE, formy odmawiania, strategie odmawiania

\section{Uwagi wstępne}

Akt mowy ODMAWIANIE towarzyszy użytkownikom języka w codziennej komunikacji, choć nie zawsze są oni skłonni do tego lub gotowi na to, aby zrealizować tę czynność mowy za pomocą tylko środków językowych i w sposób ekplicytny. Wynika to przede wszystkim z tego, że - jak podaje Alicja GAtCZYŃSKA (2005: 113) - „(a)kt ten jest [...] sprzeczny z oczekiwaniem nadawcy wypowiedzi-akcji i narusza jego godność". Potwierdza to również Silvia BonAcCHı (2011: 112), która zalicza akty odmowy do tzw. krytycznych aktów 
mowy i uzasadnia to w następujący sposób: „Verweigerungen gehören zu den kritischen Sprechakten, die auf pragmatischer Ebene gegen das Kooperationsprinzip verstoßen, da sie den Einklang zwischen Interaktanten gefährden"2.

Nie zmienia to jednak faktu, że każdy użytkownik języka dysponuje bardzo bogatą paletą środków werbalnych i niewerbalnych, za których pomocą dany akt mowy - tu ODMAWIANIE - może zostać zrealizowany. Jak bowiem podaje Eugeniusz Toмıczek (1992: 16): „Rzadko też zdajemy sobie sprawę z tego, że każdy język dysponuje sporym potencjałem form, które nie tylko umożliwiają człowiekowi działanie $w$ ramach przyjętych norm społecznych (konwencji), lecz jakże często w sposób subtelny, acz zamierzony stają się narzędziem bezpośredniego oddziaływania na partnera (partnerów) interakcji".

Przedmiotem niniejszego opracowania są formy realizacji aktu mowy ODMAWIANIE $w$ języku niemieckim. Materiał empiryczny stanowią autentyczne niemieckie listy odmowne na podania o pracę (Absageschreiben) zebrane $w$ latach 2001-2012 ${ }^{3}$. Celem analizy jest próba stworzenia typologii środków językowych, które w kontekście badanego gatunku tekstu są stosowane do udzielania odpowiedzi odmownej oraz sygnalizowania strategii przyjmowanych przez autorów przywołanych tekstów podczas formułowania odmowy.

\section{Odmowa/ODMAWIANIE - ustalenia terminologiczne}

W języku niemieckim można wyrazić odmowę eksplicytnie, stosując czasowniki, które jednoznacznie nazywają tę czynność mowy, na przykład: absagen ('odmawiać'), ablehnen ('załatwić odmownie, odrzucić, oddalić, odmówić, dezaprobować'), widerrufen ('cofnąć, odwołać'), abschlagen ('odrzucać, odmawiać, odpierać'), abschwören ('wypierać się, wyrzekać się'), absprechen ('odmawiać, pozbawiać'), abstreiten ('kwestionować, zaprzeczać'), negieren ('negować'), verneinen ('odmawiać').

Nazwa analizowanego tu rodzaju tekstu - Absageschreiben ('list odmowny') sugeruje jego treść - odmowę. Jest to nazwa złożona, w której skład wchodzi rzeczownik Absage, będący derywatem od czasownika absagen. Rzeczownik Absage jest definiowany jako: „1. a. 'Zurücknahme [eines Übereinkommens], ablehnender Bescheid': eine Absage erhalten; b. 'Ablehnung, Zurückweisung': eine Absage an totalitäre Politik. 2. (Rundf.) 'am Schluss einer Sendung folgende Bemerkungen des Ansagers'”4" W kontekście niniejszego opracowania istotne jest znaczenie wskazane $w$ punkcie 1a.

1 W literaturze przedmiotu są nazywane również „sprzecznymi aktami mowy” (por. UNWERTH, BUSCHMANN, 1981).

2 Pol. „Odmowy należą do krytycznych aktów mowy, które na płaszczyźnie pragmatycznej naruszają zasadę kooperacji, ponieważ stanowią zagrożenie dla zgodnej współpracy między interlokutorami" [przeł. J.S.].

${ }^{3}$ Obecnie $w$ Niemczech listy odmowne na podania o pracę są $w$ przeważającej części generowane przez tzw. Absagegeneratoren dostępne online, por. np. [online: https://www.absage-bewerbung. de/absagen-generator-absagen-individuell-zusammenstellen/; data dostępu: 26.09.2020]. Wynika to przede wszystkim z szablonowego charakteru struktury tego typu tekstów (por. SzczE K, 2015).

4 Pol. „1. cofnięcie, informacja odmowna; 2. (radio) słowa wypowiadane przez spikera na zakończenie audycji"; por. [online: https://www.duden.de/rechtschreibung/Absage; data dostępu: 28.09.2020]. 
Odmowa należy do responsywnych czynności mowy i ma charakter wolitywny. Jest realizowana jako reakcja na określoną sytuację, stanowi zatem element sekwencji. GAtczrńSKA (2003) wyróżnia tu trzy rodzaje sytuacji, w których może być formułowana odmowa: reakcja na akty polecenia, reakcja na akty prośby oraz reakcja na akty propozycji. Małgorzata MARCJANIK (2006: 253) wymienia również inne sytuacje komunikacyjne, w których reakcją jest odmowa: błaganie, rada, zalecenie, rzadziej rozkaz, zakaz, żądanie. Eksplikację odmowy prezentuje również Anna WierzBicka (1987: 94):

wiem, że chcesz, abym zrobił n (ponieważ tak powiedziałeś)

myślę, że sądzisz, iż to zrobię

mówię: nie chcę tego zrobić i nie zrobię tego

sądzę, że nie muszę tego zrobić, jeżeli nie chcę

mówię to, ponieważ chcę, żebyś to wiedział

sądzę, że rozumiesz, że n nie może się zdarzyć z tego powodu.

Odmowa jako taka należy zatem do reaktywnych aktów mowy, czyli:

- „wypowiedzi-reakcji na wypowiedź-akcję", przy czym wypowiedź-akcja w kontekście aktu mowy analizowanego $w$ tym artykule to akty prośby $w$ formie pisemnej (por. GAtCZYŃSKA, 2003: 30),

- aktów będących „repliką aktów dyrektywnych” (por. OPAtEK, 1974: 46),

- czynności mowy będących „wyrazem woli nadawcy” (por. GAtczrŃsKA, 2003: 33).

Na potrzeby niniejszej analizy przyjmuję definicję odmowy według MARCJANıK: „Odmowa to wypowiedź będąca negatywną reakcją na wypowiedź dyrektywną, czyli taką, której celem jest skłonienie odbiorcy do zrobienia tego, czego chce nadawca" (2006: 256). Wypowiedź dyrektywna $w$ kontekście prezentowanych rozważań to podanie o pracę, w którym formułowane są przede wszystkim akty PROŚBY lub PROPOZYCJI.

\section{Kulturowe aspekty realizacji aktu odmowy w Niemczech}

Sposób realizacji aktu mowy ODMAWIANIE jest zależny od sytuacji i determinowany przez wiele czynników, w tym pozajęzykowych, wynikających również z aspektów kulturowych. ODMAWIANIE należy bowiem do tych czynności mowy, które nie są łatwe do realizacji. Wskazuje na to MARCJANIK: „[...] odmowa nie pociąga za sobą żadnych poważnych sankcji [...]” (2014: 197), ale „konsekwencje towarzyskie odmowy są na tyle uciążliwe, że Polakom - nie przyjmującym w większości postawy asertywnej - odmawianie przychodzi z trudnością" (2014: 197).

W odniesieniu do Niemców i niemieckiej kultury językowej Bonacch (2013: 214) podaje, że charakteryzuje ich rzeczowość i w związku z tym nie mają oni trudności w mówieniu „nie”. Formułuje ponadto następujące nakazy i zakazy dotyczące realizacji tego aktu mowy przez Niemców (BonACCHI, 2013: 214):

\section{Gebote:}

Handle konsequent, sei kohärent in Wort und Tat! Betone Deine Individualität, Du wirst dafür geschätzt! Schütze Dein Recht auf Privatraum und Privatleben! 
Joanna Szczęk

Verbote:

Überschreite den Handlungsspielraum Deines Partners nicht $!^{5}$

Formułowanie odmowy $w$ niemieckiej kulturze językowej ma zatem wyraźny charakter asertywny.

\section{Typy i formy realizacji aktu odmowy $w$ świetle literatury przedmiotu}

Praktyka językowa wskazuje na dwa zasadnicze typy reakcji na akty prośby lub propozycji. To zgoda lub odmowa. Ze względu na to, że przedmiotem niniejszego opracowania są reakcje odmowne, nie uwzględniam w poniższych rozważaniach form realizacji aktu zgody.

W literaturze przedmiotu ${ }^{6}$ wyróżnia się dwa główne typy odmowy (por. IтAKuRA, 2004: 223):

1) odmowę bezpośrednią;

2) odmowę pośrednią, realizowaną za pomocą innych aktów mowy, na przykład usprawiedliwianie się, przepraszanie, wyrażanie żalu, unikanie odpowiedzi, podziękowanie.

Susan M. GAss i Noël Houck (1999: 3 i n.) wskazują na trzy formy realizacji aktu odmowy:

1) odmowa,

2) przesunięcie decyzji w czasie,

3) rozwiązania alternatywne, z których tylko pierwsza forma ma charakter kategoryczny i ostateczny.

Wśród strategii stosowanych do realizacji aktu odmowy wymieniają następujące: „conventional nonperformative refusal”, „statement of regret”, „excuse/reason/esplanation”, „proposal of alternative”, „Conformations”, „requests for clarification”, „information, agreement”7.

Leslie M. Beebe, Tomoko Takahashi i Robin Uliss-Weltz (1990: 72 i n.; cyt. za: NixDORF 2002: 44) prezentują następujący katalog reakcji odmownych:

I. Direct

A. Performative (I refuse.)

B. Non-performative statement

1. No

2. Negative willingness / ability (I can't. I won't be able to give them to you.) II. Indirect strategies

3. Regret (I'm very sorry.)

4. Explanation (I want to leave now.)

${ }^{5}$ Pol. „Nakazy: Działaj konsekwentnie, bądź spójny w słowie i czynie! Podkreślaj swoją indywidualność, za to będziesz szanowany! Strzeż swojego prawa do prywatnej przestrzeni i prywatnego życia. Zakazy: Nie przekraczaj pola działania twojego partnera!"

6 Por. również monografię Szczę (2015), której przedmiotem są reakcje odmowne na podania o pracę.

7 Pol. „konwecjonalna odmowa nieperformatywna”, „wyrażenie żalu”, „usprawiedliwienie/powód/ wyjaśnienie”, „propozycja alternatywy”, „potwierdzenia”, „prośby o wyjaśnienia”, „informacja, zgoda”. 
5. Future acceptance (I can help you tomorrow after final exam.)

6. Principle (I don't like lazy students who like easy note taking.)

7. Philosophy (ercuse is worse than sin)

8. Self defense (You should have attended clas.)

9. Criticism

10. Attack

III. Adjuncts to Refusals

11. Positive Opinion (Congratulations on your promotion. I am very glad!)

12. Gratitude (Thanks for the invitation.)

13. Agreement (Yes, I agree, but ... $)^{8}$.

Marion Grein (2007: 117) proponuje dla języka niemieckiego i japońskiego typologię możliwych reakcji odmownych. Obejmują one następujące akty mowy i ich sekwencje:

1) brak odmowy,

2) odmowa nonwerbalna,

3) tylko przeproszenie,

4) tylko odmowa,

5) tylko uzasadnienie,

6) tylko propozycja alternatywna,

7) przeproszenie + odmowa,

8) przeproszenie + uzasadnienie,

9) przeproszenie + alternatywa,

10) odmowa + uzasadnienie,

11) odmowa + alternatywa,

12) uzasadnienie + alternatywa,

13) przeproszenie + odmowa + uzasadnienie,

14) przeproszenie + uzasadnienie + alternatywa,

15) przeproszenie + odmowa + alternatywa,

16) odmowa + uzasadnienie + alternatywa,

17) przeproszenie + odmowa + uzasadnienie + alternatywa.

Nina NiXdorf (2002: 48) wymienia następujące typy rekacji odmownych w odpowiedzi na akt OFEROWANIE: 1) Nein ('nie'), 2) Will nicht ('nie chcę'), 3) Erklärung ('wyjaśnienie'), 4) Bedauern ('wyrażenie żalu'), 5) Alternative ('alternatywa'), 6) Angriff ('atak'), 7) als ob ('jak gdyby'), 8) Vermeidung ('unik'), 9) Verschiebung ('odsunięcie, przesunięcie'), 10) Themawechsel ('zmiana tematu'), 11) Wiederholung ('powtórzenie'), 12) Witz ('dowcip').

W świetle przytoczonych przykładowych typologii werbalnych form realizacji aktu odmowy można zatem stwierdzić, że katalog tych form jest bardzo bogaty. Na uwagę zasługuje fakt, że akt mowy ODMAWIANIE, formułowany w sposób bezpośredni lub pośredni,

8 Pol. I. Bezpośrednie, A. Performatywy (Odmawiam.); B. Wypowiedzi nieperformatywne; 1 . Nie, 2. Negatywna chęć/zdolność (Nie mogę. Nie będę w stanie ci ich dać.); II. Strategie niebezpośrednie; 3. Żal (Bardzo mi przykro.); 4. Wyjaśnienie (Chcę teraz wyjść.); 5. Przyszła akceptacja (Pomogę ci jutro po maturze.); 6. Zasada (Nie lubię leniwych uczniów, którzy lubia łatwe robienie notatek.); 7. Filozofia (wymówka jest gorsza niż grzech); 8. Samoobrona (Powinieneś być na zajęciach.); 9. Krytyka; 10. Atak; III. Dodatki do formułowanej odmowy; 11. Pozytywna opinia (Gratuluję awansu. Bardzo się cieszę!); 12. Wdzięczność (Dzięki za zaproszenie.); 13. Umowa (Tak, zgadzam się, ale ...). 
ze względu na swój potencjał krytyczny jest często obudowywany innymi aktami mowy, na przykład podziękowanie, wyrażenie żalu, jak pokazują przytoczone przykłady. Ich rola polega na łagodzeniu skutków formułowanej odmowy.

\section{Typy i formy realizacji aktu odmowy} $w$ świetle niemieckich listów odmownych na podania o pracę

Podstawę analizy $w$ niniejszym opracowaniu tworzą 253 autentyczne niemieckie listy odmowne na podania o pracę, które zostały zebrane w latach 2001-2012. Listy odmowne na podanie o pracę (niem. Absageschreiben) definiuję w następujący sposób: są to teksty, „die 1. auf der Grundlage einer schriftlichen Bewerbung, 2. die von einem Kommunikationspartner (= Bewerber) 3. an den anderen Kommunikationspartner (= den potentiellen Arbeitgeber) gerichtet wird, 4. von dem anderen Kommunikationspartner (= dem potentiellen Arbeitgeber) verfasst werden, 5. und eine negative Entscheidung in Bezug auf die eingereichte Bewerbung enthalten"9 (SzCzEK, 2015: 48).

\subsection{Struktura listów odmownych na podania o pracę}

Na podstawie analizy zebranych przykładów można wskazać pewne stałe elementy struktury omawianego rodzaju tekstu, które składają się na jego wzorzec. Są to:

1. Początek: elementy faktograficzne: adres nadawcy, znak/numer sprawy, adres odbiorcy, miejscowość, data.

2. Część główna: nagłówek ${ }^{10}$, formuła potwierdzenia otrzymania dokumentów aplikacyjnych (formy: stwierdzenie faktu, że złożone zostało podanie, potwierdzenie i podziękowanie za podanie, podziękowanie za zainteresowanie pracą), opis procesu rekrutacyjnego, odmowa, powody odmowy, usprawiedliwienie potencjalnego pracodawcy i pocieszenie, prośba o zrozumienie, podziękowanie za trud włożony w przygotowanie dokumentów aplikacyjnych, porady dotyczące dalszego poszukiwania pracy, wyrażenie żalu, życzenia powodzenia $w$ dalszym szukaniu pracy, informacja o odesłaniu dokumentów.

3. Zakończenie: pozdrowienia (i podpis).

Należy przy tym zaznaczyć, że odmowa bezpośrednia lub pośrednia jest formułowana w części głównej.

\subsection{Analiza materiału}

W analizowanym materiale można wyróżnić następujące typy reakcji odmownych (por. też SzCzє́, 2015):

9 Pol. „które 1. na podstawie pisemnej aplikacji, 2. która została skierowana przez jednego partnera komunikacji (aplikanta) do 3. innego partnera (potencjalnego pracodawcy), 4. zostały sformułowane przez tego innego partnera komunikacji 5. i zawierają negatywną decyzję dotycząca aplikacji".

${ }^{10}$ Ze względu na to, że przedmiotem analizy nie jest struktura tematyczna tekstu, wymieniam tylko jej elementy bez przykładów. Analiza struktury jest przedmiotem innych prac poświęconych analizom listów odmownych. 
1. Bezpośrednia odmowa bez innych towarzyszących aktów mowy, na przykład: Leider haben wir in ... keine Stelle frei.

2. Odmowa w otoczeniu innych aktów mowy, które mogą wobec omawianego tu aktu mowy zajmować różną pozycję:

a) po akcie odmowy - są to przede wszystkim akty UZASADNIANIE, WYRAŻANIE ŻALU, DZIĘKOWANIE, ZACHECANIE, DORADZANIE; można tu wskazać na następujące sekwencje:

- ODMAWIANIE + UZASADNIENIE, na przykład: Wir können Ihrer Bewerbung als Online-Redakteur in unserer Redaktion leider nicht nachkommen, da wir keine Online-Redaktion in Berlin haben.

- ODMAWIANIE + DORADZANIE + WYRAŻENIE ŻALU, na przykład: Auf Ihre Bewerbung muss ich Ihnen mitteilen, dass in meinem Geschäftsbereich zur Zeit keine für Sie geeignete Stelle zu besetzen ist. Ich bitte Sie, die Stellenausschreibungen in der Presse zu verfolgen und sich gegebenenfalls zu einem späteren Zeitpunkt nochmals zu bewerben. [...] Ich bedauere, Ihnen keine andere Nachricht geben zu können.

- ODMAWIANIE + UZASADNIANIE + WYRAŻANIE ŻALU + DZIEKOWANIE, na przykład: Ihre Bewerbung um die o.g. Stelle konnte bei der Stellenbesetzung leider nicht berücksichtigt werden, da ich mich für einen anderen Bewerber entschieden habe. Ich bedauere, Ihnen keine günstigere Mitteilung machen zu können und danke Ihnen für das gezeigte Interesse.

b) przed aktem odmowy - to przede wszystkim wyrażanie żalu, potwierdzanie, dziękowanie, doradzanie, uzasadnianie, prośba; również tutaj można wskazać na kombinacje wskazanych aktów mowy z odmową; są to:

- WYRAŻANIE ŻALU + ODMAWIANIE, na przykład: Zu unserem Bedauern müssen wir Ihnen jedoch mitteilen, dass wir Ihnen keine Ihren Qualifikationen entsprechende Position anbieten können. [...]

- DZIEKOWANIE + ODMAWIANIE, na przykład: Vielen Dank für die Zusendung Ihrer Bewerbung. Nach sorgfältiger Prüfung Ihrer Unterlagen teilen wir Ihnen mit, dass die Möglichkeit einer Einstellung in ... zurzeit nicht gesehen wird. [...]

- DZIEKKOWANIE + WYRAŻANIE ŻALU + ODMAWIANIE, na przykład: Vielen Dank für die Zusendung Ihrer Bewerbungsunterlagen ... Wir bedauern, Ihnen mitteilen zu müssen, dass es in absehbarer Zeit keine freie Stelle in unserer Online-Redaktion geben wird. [...]

- DZIEKOWANIE + WYRAŻANIE ŻALU + UZASADNIANIE + ODMAWIANIE, na przykład: Wir danken Ihnen für Ihre Bewerbung als ... in unserem Unternehmen. $\mathrm{Zu}$ unserem Bedauern müssen wir Ihnen mitteilen, dass wir Ihnen aufgrund eines unbefristeten Einstellungstopps keine Stelle anbieten können. [...]

- POTWIERDZANIE + UZASADNIANIE + DORADZANIE + WYRAŻANIE ŻALU + ODMAWIANIE, na przykład: Ihre an den Senat von Berlin gerichtete Bewerbung ist mir zur Beantwortung zugeleitet worden. Aufgrund der schwierigen Haushaltssituation des Landes Berlin bestehen innerhalb der gesamten Berliner Verwaltung gegenwärtig keine Möglichkeiten, Neueinstellungen vorzunehmen. Nach Aufhebung der zur Zeit verhängten Stellenbesetzungssperre im öffentlichen Dienst werden frei werdende Stellen jedoch zu gegebener Zeit in der Tagespresse bzw. im Amtsblatt für 
Berlin ausgeschrieben, so dass es Ihnen freisteht, sich auf eine Stelle, die Ihren Interessen und Ihrer Qualifikation entspricht, erneut zu bewerben. Ich bedauere, Ihnen keine bessere Mitteilung machen zu können.

- DZIEKOWANIE + UZASADNIANIE + WYRAŻANIE ŻALU + ODMAWIANIE, na przykład: Herzlichen Dank für Ihre Bewerbung als ... . Da wir nur eine limitierte Anzahl von Redakteurplätzen vergeben, bitten wir um Verständnis, dass wir Sie für das laufende Jahr nicht mehr einplanen können.

c) przed aktem odmowy i po nim - można tu wskazać na następujące sekwencje:

- WYRAŻANIE ŻALU + ODMAWIANIE + DZIEKOWANIE, na przykład: Zu meinem Bedauern muss ich Ihnen mitteilen, dass Ihre Bewerbung bei der Personalentscheidung nicht berücksichtigt werden konnte. Für Ihr Interesse an einer Mitarbeit in ... möchte ich Ihnen nochmals danken [...].

- UZASADNIANIE + ODMAWIANIE + WYRAŻANIE ŻALU, na przykład: Leider besteht in meiner Verwaltung in überschaubarer Zeit keine für Sie geeignete Beschäftigungsmöglichkeit. Aus diesem Grunde vermag ich Ihrer Bewerbung zu meinem Bedauern nicht zu entsprechen.

- POTWIERDZANIE + ODMAWIANIE + DZIEKOWANIE, na przykład: Ihre Bewerbung vom ... haben wir erhalten. Nach eingehender Prüfung müssen wir Ihnen leider mitteilen, dass wir keine Möglichkeit sehen, Sie als Mitarbeiter in unserem Unternehmen zu beschäftigen. [...] Für das unserer Firma entgegengebrachte Interesse bedanken wir uns herzlich [...].

- POTWIERDZANIE + ODMAWIANIE + ZALECANIE, na przykład: Sie haben sich bei uns beworben [...] Leider muss ich Ihnen mitteilen, dass in unserem Geschäftsbereich zum gegenwärtigen Zeitpunkt keine geeignete freie Stelle zu besetzen ist. [...] Als Empfehlung verweise ich Sie darauf, dass sämtliche Stellen des Landes Berlin, die zukünftig zu besetzen sind, im Amtsblatt von Berlin veröffentlicht werden.

- POTWIERDZANIE + DZIEKOWANIE + ODMAWIANIE + WYRAŻANIE ŻALU, na przykład: Ich bestätige den Eingang Ihrer Bewerbung vom ... und danke Ihnen für Ihr Interesse an der Mitarbeit in ... Leider ist es mir nicht möglich, Ihnen einen Ihrem Wunsch entsprechenden Arbeitsplatz in ... anbieten zu können. Ich bedauere, Ihnen keine andere Mitteilung zukommen lassen zu können.

- POTWIERDZANIE + DZIEKKOWANIE + ODMAWIANIE + UZASADNIANIE + DORADZANIE + WYRAŻANIE ŻALU, na przykład: Ich bestätige den Eingang Ihrer Bewerbung vom ... und bedanke mich für Ihr Interesse an einer Mitarbeit in ... Leider ist für die von Ihnen gewünschte Tätigkeit zur Zeit keine Stelle frei, so dass ich Ihre Bewerbung nicht berücksichtigen kann. Im Personalbereich sind außerdem umfangreiche Stellenreduzierungen umzusetzen, wodurch ein erheblicher Personalüberhang entsteht. [...] Im Falle des Freiwerdens einer entsprechenden Stelle werden wir eine öffentliche Ausschreibung vornehmen, so dass Sie sich zu diesem Zeitpunkt gezielt bewerben können. [...] Ich bedauere, Ihnen keinen günstigeren Bescheid erteilen zu können.

- POTWIERDZANIE + UZASADNIANIE + ODMAWIANIE + WYRAŻANIE ŻALU + DZIEKOWANIE, na przykład: Wir kommen zurück auf Ihre o.g. Bewerbung. Bei der Vielzahl der eingegangenen Bewerbungen war es für uns nicht einfach, eine Entscheidung zu treffen und nach Prüfung der Unterlagen müssen wir Ihnen heu- 
te leider mitteilen, dass Ihre Bewerbung nicht in die engere Wahl gekommen ist. [...] Wir bedauern Ihnen keinen positiven Bescheid geben zu können und danken für das unserem Unternehmen entgegengebrachte Interesse.

- POTWIERDZANIE + WYRAŻANIE ŻALU + ODMAWIANIE + UZASADNIANIE, na przykład: Bezug nehmend auf Ihre Bewerbung vom ... müssen wir Ihnen zu unserem Bedauern einen ablehnenden Bescheid zukommen lassen, da es uns wegen des bestehenden Einstellungsstopps nicht möglich ist, Ihnen den gewünschten Arbeitsplatz zur Verfügung zu stellen.

- DZIEKKOWANIE + ODMAWIANIE + ZACHECANIE, na przykład: Haben Sie vielen Dank für Ihre Bewerbung vom ... Leider kann ich in unserer Redaktion keinen Platz für Sie finden. Dies soll Sie aber nicht entmutigen, denn die Konkurrenz ist einfach ungeheuer hart.

- DZIEKOWANIE + ODMAWIANIE + DZIEKOWANIE, na przykład: Vielen Dank für Ihre Bewerbung, die wir mit Interesse gelesen haben. Leider müssen wir Ihnen mitteilen, dass wir Ihre Bewerbung bei der zu treffenden engsten Auswahl nicht berücksichtigen konnten. Wir danken Ihnen noch einmal sehr herzlich für das entgegengebrachte Interesse.

- DZIEKOWANIE + ODMAWIANIE + WYRAŻANIE ŻALU, na przykład: Für Ihr Schreiben vom ... darf ich Ihnen danken. Leider sehe ich in ... keine Möglichkeit einer Mitarbeit als .... Ich bedauere, Ihnen keine andere Auskunft geben zu können.

- DZIEKOWANIE + ODMAWIANIE + UZASADNIANIE, na przykład: Vielen Dank für Ihre Bewerbung als ... Leider können wir Ihnen keine positive Antwort geben, denn bei uns - wie Sie sicher in den Medien verfolgt haben - herrscht ein weiteres Einstellungsstopp.

- DZIEKOWANIE + ODMAWIANIE + WYRAŻANIE RADOŚCI, na przykład: Vielen Dank für Ihre Bewerbung und Ihr Interesse am ... Leider müssen wir Ihnen mitteilen, dass wir alle relevanten Positionen bereits besetzt haben und Ihnen daher keine Anstellung bei ... anbieten können. Wir haben uns dennoch gefreut, dass Sie sich mit Ihrer Bewerbung an unseren Sender gerichtet haben.

- DZIEKOWANIE + ODMAWIANIE + DORADZANIE, na przykład: Vielen Dank für Ihre Bewerbung und Ihr Interesse an unserem Unternehmen. Wir haben Ihre Bewerbung geprüft. Leider können wir Ihnen zur Zeit keine Ihren Erwartungen und Qualifikationen entsprechende Einsatzmöglichkeit anbieten. Sie können sich aber gerne auf der Jobbörse ... nach interessanten Stellen informieren und sich dann online bewerben.

- DZIEKOWANIE + ODMAWIANIE + OBIECYWANIE, na przykład: Nochmals vielen Dank für Ihr Interesse an einer Tätigkeit in unserem Hause. Im Moment haben wir keine Ihren Wünschen und Fähigkeiten entsprechende vakante Stelle zu besetzen. Ihr Bewerbungsschreiben lege ich gern auf Wiedervorlage, um zu gegebener Zeit darauf zurückgreifen zu können.

- DZIEKOWANIE + ODMAWIANIE + ZACHECANIE + WYRAŻANIE ŻALU, na przykład: Wir danken Ihnen nochmals für Ihre Bewerbung und das damit gezeigte Interesse an einer Mitarbeit in unserem Unternehmen. Nach Überprüfung eines möglichen Einsatzes müssen wir Ihnen leider mitteilen, dass z. Zt. entsprechend 
Ihrer Qualifikation keine Einsatzmöglichkeit gegeben ist. Bitte sehen Sie daher unsere Entscheidung nicht als negative Bewertung Ihrer persönlichen und fachlichen Qualifikationen. Wir bitten um Ihr Verständnis [...].

- DZIEKOWANIE + ODMAWIANIE + WYRAŻANIE ŻALU + PROŚBA, na przykład: Vielen Dank für das Interesse an einer Mitarbeit in ... Leider haben wir zur Zeit nicht die Möglichkeit neue Mitarbeiter einzustellen oder freie Mitarbeiter zu beschäftigen. Ich bedauere, dass ich Ihnen keinen positiven Bescheid geben kann und bitte um Ihr Verständnis.

- DZIEKKOWANIE + ODMAWIANIE + UZASADNIANIE + WYRAŻANIE ŻALU, na przykład: Vielen Dank für Ihre Bewerbung [...] Nach Prüfung der Vakanzen in den Fachabteilungen müssen wir Ihnen jedoch leider mitteilen, dass wir zur Zeit ... über keine offenen Stellen verfügen. [...] Wir bedauern Ihnen keine bessere Nachricht geben zu können.

- DZIEKKOWANIE + ODAMWIANIE + UZASADNIANIE + DORADZANIE, na przykład: Für das Interesse an einer Tätigkeit in ... danke ich Ihnen. [...] Leider muss ich Ihnen mitteilen, dass in absehbarer Zeit nicht mit weiteren Einstellungen in ... $z u$ rechnen ist. Angesichts der Stelleneinsparungsauflagen sind sowohl in diesem und voraussichtlich im nächsten Jahr keine oder in sehr geringem Umfang Einstellungsmöglichkeiten gegeben. Das ... schreibt vakante Dienstposten, für die externe Bewerber in Frage kommen, grundsätzlich in der FAZ aus.

- DZIEKOWANIE + ODMAWIANIE + UZASADNIANIE + ZACHECANIE, na przykład: Wir bedanken uns für die Einreichung Ihrer Bewerbungsunterlagen und Ihr Interesse an einer Mitarbeit in unserem Unternehmen. Wir haben inzwischen eine Vorauswahl getroffen. Leider konnten wir Ihre Bewerbung nicht in die engere Wahl ziehen - wir haben uns für einige Kandidatinnen und Kandidaten entschieden, deren Profil noch genauer den Anforderungen der ausgeschriebenen Position entspricht. Bitte sehen Sie unsere Entscheidung nicht als Bewertung Ihrer Kenntnisse und Fähigkeiten an.

- DZIEKOWANIE + ODMAWIANIE + UZASADNIANIE + ZACHECANIE + WYRAŻANIE ŻALU, na przykład: Vielen Dank für Ihre Bewerbung und das damit bekundete Interesse an unserem Unternehmen. Nach sorgfältiger Prüfung der eingegangenen Bewerbungen müssen wir Ihnen heute leider mitteilen, dass Sie nicht in die engere Wahl gekommen sind. Sie werden sicherlich wissen, dass bei mehreren guten und qualifizierten Bewerberinnen und Bewerbern oft nur Details über die Besetzung einer Position entscheiden. Bitte sehen Sie in unserer Absage nicht ein Werturteil über Ihre persönliche oder fachliche Qualifikation. Wir bedauern Ihnen keine günstigere Nachricht geben zu können [...].

- DZIEKOWANIE + ODMAWIANIE + DORADZANIE + WYRAŻANIE ŻALU, na przykład: Für Ihre Bewerbung und das damit verbundene Interesse an einer Tätigkeit in ... danke ich Ihnen. [...] Ich muss Ihnen leider mitteilen, dass [...] zur Zeit keine freie Stelle zu besetzen hat, so dass Ihrer Bewerbung nicht näher getreten werden kann. Sofern Stellen für eine externe Besetzung vorgesehen sind, werden diese grundsätzlich in der regionalen bzw. überregionalen Presse, über das Internet, sowie über die zuständigen Dienststellen der Arbeitsverwaltung veröffentlicht. Ich bedauere, Ihnen keine günstigere Mitteilung geben zu können. 
- DZIEKOWANIE + ODMAWIANIE + DORADZANIE + ZACHECANIE + DZIEKKOWANIE, na przykład: Ich danke Ihnen für Ihre Bewerbung bei ... Leider muss ich Ihnen mitteilen, dass zur Zeit keine passende Stelle frei ist. Ich möchte Sie aber darauf hinweisen, dass freiwerdende Stellen in der Berliner Tagespresse und auf unserer Website ... ausgeschrieben werden. Sollte eine für Sie geeignete Stelle inseriert werden, zögern Sie nicht, sich erneut zu bewerben. Ich bedanke mich für Ihr Interesse an einer Tätigkeit in ... [...].

- DZIEKOWANIE + ODMAWIANIE + DORADZANIE + WYRAŻANIE ŻALU, na przykład: Für Ihre Bewerbung und das damit bekundete Interesse an einer Tätigkeit in ... danken wir Ihnen. Leider müssen wir Ihnen jedoch mitteilen, dass in absehbarer Zeit keine Ihren Fähigkeiten entsprechende Stelle vakant ist. Ergänzend hierzu informieren wir Sie, dass auch in den nächsten Jahren kaum Dauerstellen zu besetzen sein werden. Unsere aktuellen Stellenausschreibungen [...] finden Sie im Internet. Wir bedauern Ihnen keine günstigere Mitteilung geben zu können.

- DZIEKOWANIE + DZIEKOWANIE + ODMAWIANIE + UZASADNIANIE + PROŚBA + WYRAŻANIE ŻALU, na przykład: Vielen Dank für Ihre Bewerbung und das damit verbundene Interesse an unserem Unternehmen. Ferner möchten wir uns bei Ihnen für Ihre Geduld bedanken. Leider müssen wir Ihnen mitteilen, dass wir Sie trotz Ihrer interessanten Bewerbung nicht in die engere Wahl genommen haben. Letztendlich kommt es bei der Auswahl des passenden Bewerbers auf eine Vielzahl von Faktoren an, die einen Gesamteindruck ergeben, den wir auch nur abschätzen können. Bei der Vielzahl an qualifizierten Bewerbungen ist es uns nicht leicht gefallen eine Entscheidung zu treffen und wir bitten Sie deshalb diese Absage nicht als Kritik an Ihrer eigenen Person zu sehen. Wir bedauern, Ihnen keinen positiven Bescheid mitteilen zu können.

- DZIEKOWANIE + WYRAŻANIE ŻALU + ODMAWIANIE + UZASADNIANIE, na przykład: Für Ihr Interesse an einer Mitarbeit in unserem Hause danken wir Ihnen, können jedoch zu unserem Bedauern von Ihrer Bewerbung keinen Gebrauch machen, weil geeignete Arbeitsplätze nicht zur Verfügung stehen.

- DZIEKOWANIE + WYRAŻANIE ŻALU + ODMAWIANIE + POLECANIE, na przykład: Wir danken Ihnen für Ihre Bewerbung um eine Beschäftigung bei ..., bedauern jedoch, Ihnen mitteilen zu müssen, dass eine für Sie geeignete Stelle zur Zeit nicht $z$ z besetzen ist. Da derartige Stellen von uns grundsätzlich öffentlich ausgeschrieben werden, empfehlen wir Ihnen, auf unsere Stellenausschreibungen zu achten [...] und sich ggf. gezielt zu bewerben.

- DZIEKOWANIE + WYRAŻANIE ŻALU + ODMAWIANIE + DZIEKOWANIE, na przykład.: Wir danken Ihnen für Ihre Bewerbung. Zu unserem Bedauern müssen wir Ihnen mitteilen, dass wir keinen für Sie in Frage kommenden Arbeitsplatz zu vergeben haben. Wir möchten Ihnen für das Interesse danken, das Sie unserem Unternehmen entgegengebracht haben.

- DZIEKOWANIE + WYRAŻANIE ŻALU + UZASADNIANIE + ODMAWIANIE + DZIEKOWANIE + WYRAŻANIE ŻALU, na przykład: Ich danke für Ihre Bewerbung vom ... um eine Stelle als ... Zu meinem Bedauern muss ich Ihnen mitteilen, dass ich aufgrund der Sparpolitik des Berliner Senats [...] leider keine Möglichkeit sehe, Ihnen eine Ihrer Qualifikation entsprechende Beschäftigung anbieten zu können. Ich danke 
für das an einer Tätigkeit in meiner Verwaltung gezeigte Interesse und bedauere, Ihnen keinen günstigen Bescheid erteilen zu können.

- DZIEKOWANIE + UZASADNIANIE + ODMAWIANIE + PROŚBA + DZIEKOWANIE, na przykład: Zunächst möchten wir uns für Ihre Bewerbung und das unserem Theater entgegengebrachte Interesse bedanken. Bedauerlicherweise kommt man bei Stellenausschreibungen immer in die gleiche Situation, wir müssen eine Reihe guter Bewerber ablehnen, da es einen mit noch besseren Voraussetzungen gibt. Leider müssen wir das auch in Ihrem Falle tun. Für diese Entscheidung, die in keiner Weise ein persönliches oder fachliches Werturteil darstellt, bitten wir um Ihr Verständnis. [...] Wir danken Ihnen für Ihr Verständnis und Ihre Geduld [...].

- DZIEKOWANIE + UZASADNIANIE + ODMAWIANIE + DORADZANIE + WYRAŻANIE ŻALU, na przykład: Vielen Dank für Ihr Interesse an einer Tätigkeit als ... bei ... . Wir erhalten wöchentlich eine Vielzahl von ähnlich qualifizierten Bewerbungen, die nur einer sehr begrenzten Anzahl von offenen Stellen gegenüberstehen. Zum jetzigen Zeitpunkt sind bedauerlicherweise keine Ihren Qualifikationen entsprechenden Vakanzen vorhanden. Sofern freiwerdende oder neu eingerichtete Stellen der Bundesverwaltung extern zu besetzen sein sollten, werden sie unter Angabe der erforderlichen Qualifikation bundesweit ausgeschrieben. Des Weiteren finden Sie die Stellenangebote unter... Ich bedauere, Ihnen keine günstigere Mitteilung machen zu können [...].

- WYRAŻANIE RADOŚCI + WYRAŻANIE ŻALU + ODMAWIANIE + PROŚBA, na przykład: Über Ihre Bewerbung um eine Einstellung bei ... habe ich mich gefreut. Zu meinem Bedauern stehen mir keine freien Stellen zur Verfügung, so dass ich Ihrem Einstellungswunsch leider nicht entsprechen kann. Ich bitte hierfür um Verständnis.

W grupie przytoczonych tu kombinacji aktów mowy, które $w$ niemieckich listach odmownych na podania o pracę lokują się z aktem ODMAWIANIA, można wyróżnić dwa pola ich występowania: przed aktem odmawiania i po akcie odmawiania. Tendencję do występowania $w$ lewym polu - przed ODMAWIANIEM - wykazują WYRAŻANIE ŻALU, DZIEKOWANIE, POTWIERDZANIE, DORADZANIE, PROŚBA. W prawym polu - po odmowie - lokują się z kolei takie akty mowy, jak UZASADNIANIE, WYRAŻANIE ŻALU, DORADZANIE, DZIEKKOWANIE. Można to przedstawić $w$ następujący sposób (rys. 1):

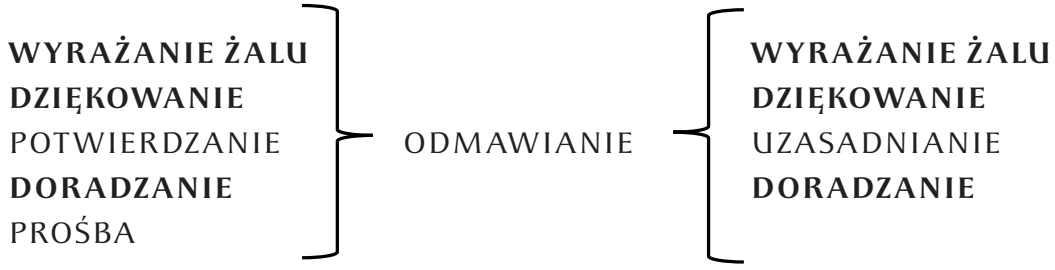

Rys. 1. Współwystępowanie aktów mowy z aktem ODMAWIANIA Źródło: Opracowanie własne.

W tabeli 1 prezentuję zestawienie kombinacji aktów mowy towarzyszących ODMAWIANIU. 
Tabela 1

Akty mowy występujące przed odmową i po odmowie w niemieckich listach odmownych na podania o pracę*

\begin{tabular}{|c|c|c|c|c|c|c|c|c|c|c|c|c|}
\hline $\mathbf{W Z}$ & WR & $\mathbf{U Z}$ & POT & D & $\mathbf{W} \dot{Z}$ & ZAL & $\mathbf{U Z}$ & DOR & ZACH & WR & OB & $\mathbf{P}$ \\
\hline \multirow[t]{7}{*}{+} & & & & & & & & & & & & \\
\hline & & + & & & + & & & & & & & \\
\hline & & & + & & & & & & & & & \\
\hline & & & + & & & + & & & & & & \\
\hline & & & + & & + & & & & & & & \\
\hline & & & + & + & + & & + & + & & & & \\
\hline & & + & + & & + & & & & & & & \\
\hline \multirow[t]{18}{*}{+} & & & + & & & & + & & & & & \\
\hline & & & & + & & & & & + & & & \\
\hline & & & & + & & & & & & & & \\
\hline & & & & + & + & & & & & & & \\
\hline & & & & + & & & + & & & & & \\
\hline & & & & + & & & & & & + & & \\
\hline & & & & + & & & & + & & & & \\
\hline & & & & + & & & & & & & + & \\
\hline & & & & + & & & & & + & & & + \\
\hline & & & & + & + & & & & & & & + \\
\hline & & & & + & + & & + & & & & & \\
\hline & & & & + & & & + & + & & & & \\
\hline & & & & + & & & + & & + & & & \\
\hline & & & & + & + & & + & & + & & & \\
\hline & & & & + & + & & & + & & & & \\
\hline & & & & + & & & & + & + & & & \\
\hline & & & & + & + & & & + & & & & \\
\hline & & & & + & + & & + & & & & & + \\
\hline+ & & & & + & & & + & & & & & \\
\hline+ & & & & + & & + & & & & & & \\
\hline+ & & & & + & & & & & & & & \\
\hline+ & & + & & + & + & & & & & & & \\
\hline & & & & + & & & & & & & & + \\
\hline & & + & & + & + & & & + & & & & \\
\hline+ & + & & & & & & & & & & & + \\
\hline
\end{tabular}

* Dla zestawienia $w$ tabeli przyjęto następujące skróty: WŻ - WYRAŻANIE ŻALU, WR WYRAŻANIE RADOŚCI, UZ - UZASADNIENIE, POT - POTWIERDZENIE, D - DZIEKOWANIE, ZAL - ZALECANIE, DOR - DORADZANIE, ZACH - ZACHECANIE, OB - OBIECYWANIE, $P$ - PROŚBA. 
Na tej podstawie można wskazać akty mowy, które najczęściej współwystępują z odmową w analizowanym gatunku tekstu. Są to DZIÉKOWANIE, WYRAŻANIE ŻALU, UZASADNIANIE.

\section{Wnioski}

W literaturze poradnikowej dotyczącej formułowania odmowy prezentowane są różne strategie i zalecenia dotyczące realizacji tego aktu mowy. Z jednej strony można odnaleźć ogólne porady typu „Vermitteln Sie eine Absage so konstruktiu wie möglich”"11 (HovermanN, Dohler, Siersdorfer, 2009: 5). Z drugiej zaś autorzy listów odmownych mogą korzystać z bogatej palety rozwiązań i kombinacji prezentowanych w poradnikach. Najczęściej wymieniane zalecenia to konieczność podziękowania, wyrażenia żalu oraz podania uzasadnienia odmowy. Ciekawą strategię realizacji odmowy podaje Gloria ВЕск, która wprowadza pojęcie „komplementu odmownego” i definiuje go w następujący sposób: „Komplement odmowny składa się zatem zawsze z dwóch części: 1. Komplementu jako wyrazu uznania za dotychczasowe osiągnięcia. 2. Odmowy z podkreśleniem nieuniknioności i zwrotami bezosobowymi” (2009: 160). Takie formy odmowy - jak wskazuje dalej BECK - „stały się [...] przyjętym sformułowaniem, używanym przede wszystkim w życiu zawodowym" (2009: 160).

Realizacja aktu mowy ODMAWIANIE pociąga za sobą różne, często negatywne, skutki. Nie dziwi zatem chęć poszukiwania przez użytkowników języka, tu autorów listów odmownych na podania o pracę, rozwiązań strategicznych - takich sposobów formułowania odmowy, które zmniejszałyby dyskomfort nadawcy takiego komunikatu. Wpływa to również na to, że sama odmowa rzadko jest formułowana bez współwystępowania innych aktów mowy, które mają za zadanie zmniejszenie dyskomfortu nadawcy listu odmownego i minimalizowanie skutków odmowy po stronie odbiorcy. Przedstawione w niniejszym opracowaniu przykłady zdają się potwierdzać tę tezę. Nie zmienia to oczywiście faktu, że odmowa, niezależnie od aktów mowy współwystępujących, pozostaje odmową.

\section{Literatura}

BECK G., 2009: Komplement. Sztuka uwodzenia słowem. Helion. Gliwice.

Beebe L.M., Takahashi T., Uliss-Weltz R., 1990: Pragmatic Transfer in ESL Refusals. In: Scarcella R.C., Andersen E.S., Krashen S., eds.: Developing Communicative Competence in a Second Language. Cambridge University Press. New York, s. 55-73.

BonacCHI S., 2011: Ich habe leider keine Zeit...: Kulturlinguistische Bemerkungen über höfliche Verweigerungen im deutsch-polnischen-italienischen Vergleich. In: EHRHARDT C., NEULAND E., YAMASHITA H., Hrsg.: Sprachliche Höflichkeit zwischen Etikette und kommunikativer Kompetenz. Peter Lang. Frankfurt am Main, s. 111-128.

Bonacchı S., 2013: (Un)Höflichkeit. Peter Lang. Frankfurt am Main.

11 Pol. „Proszę przekazywać odmowę tak konstruktywnie, jak tylko jest to możliwe”. 
GAtCZYŃSKA A., 2003: Akty odmowy we współczesnym języku polskim. Wydawnictwo Akademii Świętokrzyskiej. Kielce.

GAtCzYŃSKA A., 2005: Grzeczne i niegrzeczne akty odmowy w języku polskim. „Język a Kultura”, XVII, S. $113-118$

Gass S.M., Ноuск N., 1999: Interlanguage Refusals. De Gruyter. Berlin-New York.

GreIN M., 2007: Kommunikative Grammatik im Sprachvergleich. Die Sprechaktsequenz Direktiv und Ablehnung im Deutschen und Japanischen. Niemeyer. Tübingen.

Hovermann C., Dohler J., Sierdorfer A., 2009: Stilvolle Absagen im Geschäftsalltag: Wie Sie negative Informationen freundlichen und konstruktiv vermitteln. Verlag Dt. Wirtschaft. Bonn.

IтAкURA U., 2004: Absagen bei der Einkaufs-/Verkaufshandlung im Deutschen und Japanischen. Versuch einer pragmatischen Interpretation. „Deutsch als Fremdsprache”, IV, s. 220-226.

Marcjanik M., 2006: Retoryka codzienności. Zuyczaje językowe współczesnych Polaków. Trio. Warszawa.

MARCJANIK M., 2014: Słownik językowego savoir-vivre’u. Wydawnictwo Uniwersytetu Warszawskiego. Warszawa.

NIXDORF N., 2002: Höflichkeit im Englischen, Deutschen, Russischen: ein interkultureller Vergleich am Beispiel von Ablehnungen und Komplimenterwiderungen. Tectum Verlag. Marburg.

OPAŁEK K., 1974: Z teorii dyrektyw i norm. PWN. Warszawa.

SzCZEK J., 2015: Absageschreiben auf Bewerbungen. Eine pragmalinguistische Studie. Frank\&Timme. Berlin.

Tомісzек E., 1992: Z badań nad istota grzeczności językowej. „Język a Kultura”, VI, s. 15-25.

UnWerth H.J. von, Buschmann U., 1981: Konfliktive Sprechakte und Lehrwerktert. In: MüLLER B.-D., PARIS R., Hrsg.: Konfrontative Semantik. Lexika Verlag. Tübingen.

Wierziıck A., 1987: Englisch Speech Act Verbs. A Semantic Dictionary. Academic Press Inc. Sydney. 